\title{
Sex Identification Based on Lip Print Pattern
}

\author{
N Kasuma1, F N Fajrin ${ }^{2}$ \\ Faculty of Dentistry, Andalas University, Padang, West Sumatera, Indonesia ${ }^{1}$ \\ Postgraduate Program of Biomedical Science, Andalas University, Padang, West Sumatera, \\ Indonesia ${ }^{2}$ \\ \{nilakasuma@dent.unand.ac.id ${ }^{1}$,rin.inoochi@gmail.com² $\}$
}

\begin{abstract}
Human identification is essential needed to investigate criminals, mass disaster victim and certificates of death as well. In a certain case, however identification using primary data such as fingerprints, teeth, and DNA cannot be conducted because of the human body decomposition and evidence lost. So the secondary data is needed to make an easier identification. Lip print pattern provides secondary data that is unique, and easy to collect. Here we focused on determining the predominant lip print pattern to differentiate gender. The study is made of 138 people (68 males and 70 females), aged from 10 to 70 years, from Siberut, Mentawai. A 5x2 cm width cellophane tape was cut and stuck on both the lips together and pressed with even pressure for 3 seconds. Later, the tape was lifted from the lips carefully and adhere in a piece of white paper as a permanent record. The print was examined 3 times using a magnifying lens then classified using Suzuki lip pattern classification ..Percentage calculation method was used to identify the predominant lip pattern. The present study concludes that every individual has unique lip print and Type IV appears to be the most predominant pattern in males, type 1 appears to be the most predominant pattern.
\end{abstract}

Keywords: Cheiloscopy, Lip print, Forensic odontology, Identification.

\section{Introduction}

In criminal investigation and certification of death, identification of human remains is essentially needed[1]. Common method used in personal identification is anthropometry, fingerprints, sex determination, estimation of age, height measurement, and blood group [2], DNA, and dental identification [3]. Nowadays, primary data such as DNA, fingerprints, and dental identification is the most common technique in the field of forensic science. Dental identification technique (frequently called odontology forensic ) deals with individual identification based on evidence from teeth and oral tissue structure such as lip print pattern and rugae palatina [4]. When the primary data is not sufficient to analyze, the secondary data is needed. One of the secondary data is lip print pattern, which has unique pattern. This characteristic is helpful in victim investigation [5].

Lip print is the wrinkle and groove which exists in the transition zone of human lips (vermilion border)[6]. Lip print can be used as alternative forensic information source due to low costs, easy application, and accuracy. Cottone (1981) analyzed lipstick as the method to 
scan the lip print [7]. The use of lip lining in identifying and criminal investigations was proposed by Edmond Locard in 1932 [8].

West coast of Sumatera, Indonesia geographically located in major earthquake fault line. Native Mentawaian (native tribe of Mentawai) lived an archipelago located on the western coast of West Sumatera, the region which is vulnerable to natural disaster. Mentawai is comprised of 4 large inhabited islands (Siberut, South Pagai, North Pagai, and Sipora) and 40 small islands and numerous islet[9].

Sharma et al (2009) did the study on group consist of 20 males and 20 females using lipstick technique. There are no identical lip prints among the subjects of this study. This statement proves that the uniqueness of lip print is the potential recognition tool for sex and individual identification[10].

Although cheiloscopy has appeared in literature, there is still little research about this method and comparison of lip prints in different race groups in Indonesia, especially in Mentawai, West Sumatera.

\section{Research Method}

This descriptive study was planned to be carried out in Siberut Island, Mentawai, West Sumatera. the study population was female and males, each group is 75 persons. The age range is 1-70 years old. Simple random sampling was used as sampling method.

The purpose of the study was explained to all participants then they were instructed to state agreement in written informed consent. Exclusion criteria were patients who have hypersensitivity to the lipstick and lip anomalies.

The participants were between 10-60 years of age. A $10 \mathrm{~cm}$ length cellophane tape was cut and placed on both the lips together and evenly pressed for seconds. Then, the tape was lifted and taped to the paper as a permanent record.

The print was scanned. The part of lip which is examined is the center part since this part is always can be seen in every traces. The lip prints obtained were coded. Data is entered in SPSS version 17. Proportions and percentages are calculated for categorical data (quantitative data e.g. gender and lip prints categories). As this is a descriptive study, frequencies and percentage are calculated.

There was one person collecting the lip prints and one-second person classified pattern according to Suzuki - Tsuchihashi classification as follows[2]:

Type I Clear-cut grooves running vertically across the lip

Type I' The grooves are straight but disappear half-way instead of covering the entire breadth of the lip

Type II The grooves fork in their course

Type III The grooves intersect

Type IV The grooves are reticulate

Type $\mathrm{V}$ The grooves do not fall into any of the Types I-IV, and cannot be differentiated morphologically 


\section{Result}

The study was conducted on 138 subjects in the age range $14-62$ years old, consist of 60 males and 60 females. Results obtained after the analysis of all lip prints are presented in table 1, and graphically shown in Figure 1

Table 1. Distribution of Lip Pattern on Male and Female Native Mentawaians

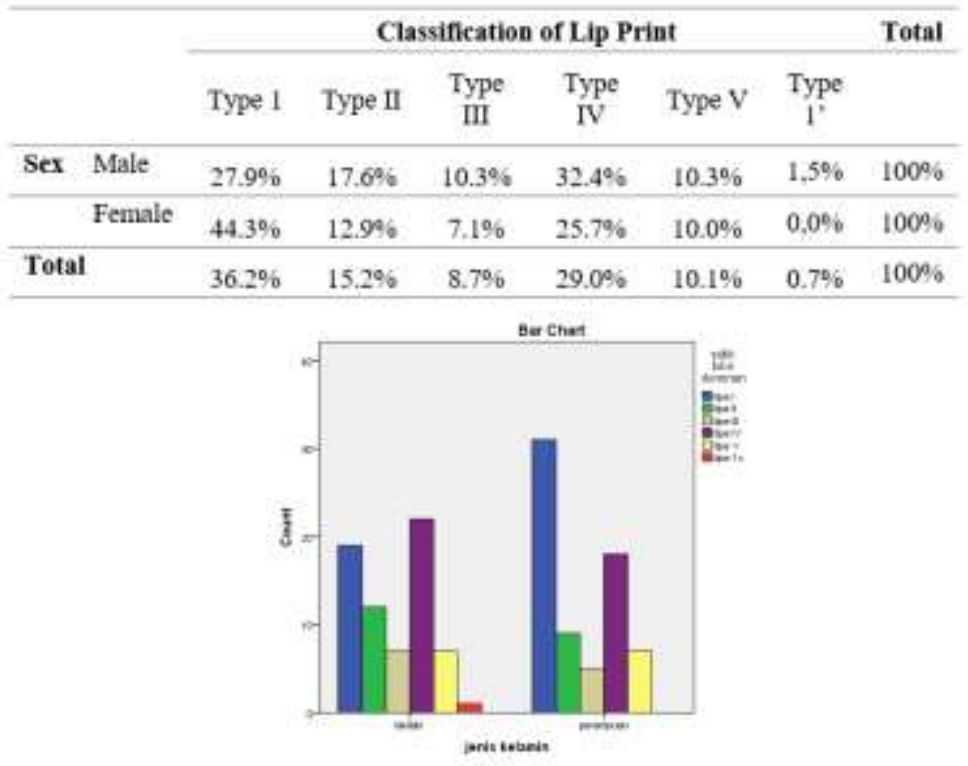

Figure 1. Distribution of Lip Pattern on Male and Female Native Mentawaians

It has been observed that type IV patterns with an average $32,4 \%$ were most predominant in Mentawaians male followed by type I, II, III and I' in descending order. Whereas type I lip patterns were most predominant with an average of $44,3 \%$ followed by type IV, II, III, and I' in descending order found in female Mentawaians.

\section{Discussion}

Cheiloscopy is an essential identification tool available in forensic odontology. Determination of individual identity by forensic methodology is warranted in cases of heir-ship, marriage, divorce, and rape[11]. When lip prints are left at the crime scenes, it can be the evidence which directing the suspect.

Tsuchihashi, the founder of the most common classification system of lip print also worked in the persistency of lip print. In a comparative study he's been into, lip print was routinely examined once a month for 3 years, then continued once in 6 months. He found that lip print has well persistency, it doesn't change significantly. In subjects which caught a cold, lip print may be obscured but it turns into the formal pattern when the cold has recovered[2].

According to a study by Vahanwala et al, the dominant pattern in female is Type I. Type III is the most common in males followed by type IV[12]. This study also has similarities in 
results with Sharma's work in 2009. In his work, it is proved that no lip prints were identical to each other. In females group, Type I and I' patterns were the most dominant pattern while in males group Type IV was the most common pattern[10].

In a criminal case, lips without lipstick which is traced in the subject cannot seen by naked eye. To prove the existence of lip print, several tools must be used so lip print can be analyzed later. Further study should be conducted to analysed the invisible lip print.

\section{Conclusions}

This descriptive study shows that in native Mentawaian, Type IV is the most dominant pattern in males, followed by Type I pattern. In females Mentawaian, Type I and IV are the most common pattern. The conclusion is the male's and female's lip print are different; therefore this can be used to differentiate gender in native Mentawai.

\section{Acknowledgments}

Our sincere thanks to the Faculty of Medicine Ethics Committee, Andalas University, and Local Government Mentawai, West Sumatera

\section{References}

[1] N. Ishaq, E. Ullah, I. Jawaad, A. Ikram, and A. Rasheed, "Cheiloscopy," Prof. Med. J., vol. 21, no. 5, pp. 883-887, 2014.

[2] Y. Tsuchihashi, "Studies on personal identification by means of lip prints," Forensic Sci., vol. 3, no. 1, pp. 233-248, 1974.

[3] N. Ishaq, U. Ehsan, I. Jawaad, A. Ikram, and A. Rasheed, “A tool for sex determination," Prof. Med J, vol. 21, no. 5, pp. 883-887, 2014.

[4] L. Kumar, V. Jayaraman, P. Mathew, S. Ramasamy, and R. Austin, "Reliability of lip prints in personal identification: An inter-racial pilot study," J. Forensic Dent. Sci., vol. 8, no. 3, p. 178, 2016.

[5] N. Nagrale, P. Murkey, and S. Patond, "Establishing cheiloscopy as a tool for identification : an assessment on 500 subjects in central India," Al Ameen J. Med. Sci., vol. 7, no. 2, pp. 201-206, 2014.

[6] S. Khanna, "Cheiloscopy: A Frequency Based Approach for IV Quadrant in Female Lip Print," J. Forensic Res., vol. 6, no. 3, pp. 1-8, Apr. 2015.

[7] S. V. Sandhu, H. Bansal, P. Monga, and R. Bhandari, "Study of lip print pattern in a Punjabi population," J. Forensic Dent. Sci., vol. 4, no. 1, p. 24, 2012.

[8] A. Narwal, S. Bala, A. Hooda, and R. Gupta, "Cheiloscopy - An Adjunct in Identification of Familial Lineage," J. Oral Heal. Community Dent., vol. 8, no. 2, pp. 82-86, 2014.

[9] K. Kusakabe, R. Shrestha, and N. Veena, Gender and land tenure in the context of disaster in Asia. Springer, 2015.

[10] P. Sharma, S. Saxena, and V. Rathod, "Cheiloscopy: The study of lip prints in sex identification," J. Forensic Dent. Sci., vol. 1, no. 1, p. 24, 2009.

[11] S. C. Bijjargi, S. B. Malligere, V. A. Sangle, F. K. Saraswathi, I. A. Majid, and S. R. Ashwinirani, "A new attempt in comparision between 3 racial groups in India - based on lip prints ( Cheiloscopy )," Int. J. Appl. Dent. Sci., vol. 1, no. 3, pp. 20-23, 2015. 
[12] S. Vahanwala, S. Pagare, and C. Nayak, "Study of Lip-prints as aid for sex determination," Medico-Legal Updat., vol. 5, no. 3, pp. 7-9, 2005. 